BULLETIN Bulletin hispanique

HISPANIQUE Université Michel de Montaigne Bordeaux

116-1 | 2014

Varia

\title{
Una visión de España en la obra de Isabel Oyarzábal de Palencia
}

Matilde Eiroa San Francisco

\section{(2) OpenEdition}

1 Journals

Edición electrónica

URL: http://journals.openedition.org/bulletinhispanique/3252

DOI: 10.4000/bulletinhispanique.3252

ISSN: 1775-3821

Editor

Presses universitaires de Bordeaux

Edición impresa

Fecha de publicación: 1 junio 2014

Paginación: 363-380

ISBN: 978-2-86781-931-5

ISSN: 0007-4640

Referencia electrónica

Matilde Eiroa San Francisco, " Una visión de España en la obra de Isabel Oyarzábal de Palencia », Bulletin hispanique [En línea], 116-1 | 2014, Publicado el 01 junio 2017, consultado el 24 mayo 2020.

URL : http://journals.openedition.org/bulletinhispanique/3252 ; DOI : https://doi.org/10.4000/

bulletinhispanique.3252

Tous droits réservés 


\title{
Una visión de España en la obra de Isabel Oyarzábal de Palencia*
}

\author{
Matilde Eiroa San Francisco \\ Universidad Carlos III de Madrid
}

Cet article a pour objectif d'analyser les contenus de la production littéraire d'Isabel Oyarzábal de Palencia, l'une des femmes les plus marquantes de la décennie 1920-1930. $Y$ sont abordées sa vision de l'Espagne et les solutions possibles apportées à divers problèmes tels que l'inégalité hommes-femmes et les causes de la Guerre Civile et de l'exil républicain.

Mots-clés : Isabel de Palencia, Guerre Civile, militantisme féminin, femmes écrivains, exil républicain espagnol.

El presente artículo tiene como objetivo analizar los contenidos de la producción literaria de Isabel Oyarzábal de Palencia, una de las mujeres con mayor ascendiente en la década de 1920-1930. En él se examina cuál fue su visión de España y las posibles soluciones a determinados problemas, como la desigualdad de las mujeres, las causas de la Guerra Civil $y$ del exilio.

Palabras claves: Isabel de Palencia, Guerra Civil, activismo femenino, mujeres escritoras, exilio republicano de 1939.

This article aims at analysing the contents of literary production of one of the women with greater influence in the decade of 1920-1930, Isabel Oyarzábal de Palencia. It examines what was her perception of Spain, and the possible solutions to diverse problems, such as equality between men and women, the causes of the Spanish Civil War and the subsequent Republican exile.

Keywords: Isabel de Palencia, Spanish Civil War, feminist activism, women writers, Spanish republican exile.

*Esta investigación forma parte de una más amplia que ha sido galardonada en el año 2013 con el XXIII Premio Victoria Kent de la Universidad de Málaga titulada Isabel de Palencia. Diplomacia, periodismo y militancia al servicio de la República. 


\section{INTRODUCCIÓN}

La generación de mujeres intelectuales, artistas y de profesiones liberales que escribió y creó cultura a principios del siglo XX vivió en un periodo de transición entre lo decimonónico y la modernidad. El contexto de la época generó un torbellino de ideas en torno a lo hispano, el imperio perdido, la modernidad, la tradición y la crisis de identidad individual y colectiva posterior al 98, un pensamiento que influyó en las mujeres de la llamada "Edad de Plata» de la cultura española y en las "modernas», tomando la denominación de S. Mangini para referirse a un conjunto de mujeres que rompieron con la tradición social de relegarlas al ámbito doméstico y a la desigualdad cultural y profesional ${ }^{1}$.

En la actualidad contamos con numerosas investigaciones procedentes de la disciplina de la literatura y de la historia que han puesto de manifiesto la brillante producción de las mujeres en el marco del triángulo más prolífico de la participación femenina en el espacio público: la literatura, el periodismo y la política. En las aportaciones se advierte acerca de los estilos, las temáticas, las coyunturas socio-históricas y las reivindicaciones de las primeras décadas del siglo XX y se descubren nombres de las más relevantes o, al menos, de las que se han encontrado las suficientes evidencias que permiten recuperar el legado cultural que construyeron ${ }^{2}$.

P. Nieva de la Paz localizó a escritoras, compositoras, escenógrafas, periodistas y otras profesiones afines en fuentes diversas que le han llevado a concluir con la existencia de un grupo, el de las más conocidas, que incluiría a Magda Donato, Carmen de Burgos, Concha Espina, Elena Fortún, Concha Méndez y María Martínez Sierra, frente a otro núcleo compuesto por aquellas casi olvidadas entre las que figuran Pilar Algora, Halma Angélico, Elena Arcediano, Sofía Blasco, Matilde Ras e Isabel Oyarzábal ${ }^{3}$. Casi todas nacieron a fines del siglo XIX y sus años más sobresalientes coinciden o están influidos por la II República. Su trabajo intelectual giraba en torno a Espańa y la mujer, un binomio vinculado

1. Shirley Mangini, Las modernas de Madrid. Las grandes intelectuales españolas de la vanguardia, Barcelona, Península, 2001. Mercedes Gómez Blesa, «Escribo, luego existo: las ensayistas de la Edad de Plata", Revista de Occidente, no 323, 2008, pp. 74-90.

2. El listado de investigaciones sería muy prolijo y enumeraremos muchos de ellos a lo largo de las páginas que siguen. Destacaremos aquí sólo algunos trabajos, como los recogidos en el número de 2011 de la revista Migraciones y Exilios. Cuadernos de AEMIC, dedicado a la literatura de mujeres exiliadas. Igualmente, Rosa Arias, Escritoras españolas (1939-1975): poesía, novela y teatro, Madrid, Editorial del Laberinto, 2005. Margherita Bernard y otras, (eds.) Papel de mujeres/ mujeres de papel. Periodismo y comunicación del siglo XIX a nuestros días, Bérgamo, University Press-Sestante edizioni, 2008. Nuria Capdevila-Argüelles, Autoras inciertas. Voces olvidadas de nuestro feminismo, Madrid, Horas y horas editorial, 2008. Amparo Hurtado, «Biografía de una generación: las escritoras del noventa y ocho", en I. Zavala (coord.), Breve historia feminista de la literatura española. La literatura escrita por la mujer (Del siglo XIX a la actualidad), Barcelona, Anthropos-Edur, 1988.

3. Pilar Nieva de la Paz, Autoras dramáticas españolas entre 1918 y 1936. (Texto y representación), Madrid, CSIC, 1993. 
de forma sutil y profunda al compartir adversidades heredadas desde antańo. Dejaron lo decimonónico en su pasado vital, cerrando las tradiciones que las ataban e impedían un alto grado de emancipación, una cuestión que se observa en las contradicciones y paradojas de su obra, fruto de vivir a caballo entre dos épocas. Para muchas de ellas el derecho a la educación era prioritario al derecho al voto y esta prelación se justificaba en la firme creencia consistente en que atesorar formación superior era la única vía de regeneración de España.

EL PERFIL DE UNA MUJER SINGULAR: Isabel de Palencia y SU pRoyección pública

El retrato identitario de Isabel Oyarzábal es la suma de un compendio de circunstancias, sentimientos y especialidades profesionales que conforman un perfil de mujer nada habitual ${ }^{4}$.

Isabel Oyarzábal Smith o Isabel de Palencia, como le gustaba presentarse desde que se casó en 1909, era una malagueña nacida en 1878 en el seno de una familia perteneciente a la burguesía conservadora. De madre escocesa, recibió una educación bilingüe y religiosa que pronto se cuestionó. No cursó estudios superiores, siendo la mayor parte de su formación autodidacta.

La lectura y el teatro constituyeron una pasión que la acompańaron a lo largo de su vida como lo muestra la lectura de libros clásicos ingleses y españoles, especialmente obras teatrales, a pesar de que la biblioteca familiar prescindiera de autores no católicos. Siendo todavía muy joven escribió un primer texto inédito a escondidas, una actitud irreverente e impensable para quienes la conocían. Esa autora juvenil utilizaba la creación literaria para expresar a través de otros personajes sus inclinaciones y personalidad.

Oyarzábal cultivó el teatro, la escritura autobiográfica, el discurso, el ensayo, el artículo corto y la columna periodística, formando parte de ese grupo de mujeres polifacéticas protagonistas del gran activismo social del primer tercio del siglo XX. En sus obras exhibió una gran fortaleza y un perfil de superviviente de una época y, sobre todo, expresó su convicción acerca de la igualdad intelectual de la mujer y del relevante papel que desempeñaba en la sociedad.

$\mathrm{Su}$ trayectoria vital transcurrió desde un posicionamiento conservador propio de las familias burguesas de la época hasta un intenso compromiso político con la izquierda a partir de la década de 1920. Formó parte de las redes femeninas más importantes y modernas, como la Asociación Nacional de Mujeres Españolas (ANME), fue presidenta del Consejo Feminista de España y una de las fundadoras del Lyceum Club de Madrid, a partir del cual se consolidó como una de las mujeres más importantes del mundo cultural y

4. Véase su biografía en Juan Carlos Sánchez Illán (dir.), Diccionario biográfico del exilio español de 1939. Los periodistas, Madrid, Fondo de Cultura Económica, 2011. Datos en Archivo Nacional de Cataluña (en adelante ANC), Fondo Isabel Oyarzábal, Inventario número 687, Registro 1812. 
feminista coetáneo, y se afilió al PSOE y a la UGT en 1931. El gobierno de la República la nombró delegada en la Sociedad de Naciones y en la Organización Internacional del Trabajo, instituciones en las que intervino con propuestas en defensa de la mujer, del niño, en contra de la esclavitud y otras formas de explotación humana así como del programa político republicano. En numerosas ocasiones se la requirió para impartir conferencias en Gran Bretaña, Estados Unidos y Canadá acerca de los temas de su especialidad -mujeres e infancia-, o para exponer las propuestas de los gobiernos a los que representó. Aprobó las oposiciones a inspectora de trabajo en 1933, y fue nombrada ministra plenipotenciaria en Suecia en octubre de 1936, siendo así la primera embajadora de España. Su ámbito de actuación fue ampliado al año siguiente a Noruega, Finlandia y Dinamarca.

En abril de 1939, cuando se encontraba en Estocolmo en su puesto de diplomática, se vio obligada a salir exiliada a México junto a su familia, y nunca más retornó a España. En su nueva situación, a la que llegó con la edad de 60 años, continuó con su actividad propagandística, escritora y periodística, especialmente los primeros años de su estancia.

La obra de I. de Palencia apenas está estudiada y resulta difícil localizar. En la actualidad va siendo conocida a través de la traducción y reedición de sus dos libros autobiográficos I must have liberty y Smouldering freedom ${ }^{5}$, las referencias a su nombre y actuación en otros estudios sobre mujeres contemporáneas, las investigaciones breves sobre aspectos específicos de su dilatada actividad profesional ${ }^{6}$ e incluso se ha realizado una tesis doctoral publicada como monografía ${ }^{7}$.

5. I must have liberty (1940), traducido y editado por Nuria Capdevilla-Argüelles como $\mathrm{He}$ de tener libertad, Madrid, Horas y horas la editorial, 2010; y Hambre de Libertad: memorias de una embajadora republicana, prólogo de Aurora Luque, Málaga, Editorial Almed, 2011. Su segunda autobiografía es Smouldering freedom. The story of the Spanish republicans in exile (1945), traducido y editado por Ma del Mar Mena Pablos como Rescoldos de Libertad, Málaga, Alfama, 2008. Josebe Martínez, «I must have liberty, para una arqueología sobre la recepción internacional de la Guerra Civil», en M. Aznar (eds.), Escritores, editoriales y revistas del exilio republicano de 1939, Sevilla, Biblioteca del Exilio-Renacimiento, 2006, pp. 807-813.

6. Antonia Rodrigo, «Isabel Oyarzábal de Palencia, primera embajadora de la República», en M. Aznar, El exilio literario español de 1939. Actas del Primer Congreso Internacional, Barcelona, Gexel-Universitad Autónoma de Barcelona, 1998, Vol. I., p. 341-348. Rosa Ma Ballesteros, «Isabel Oyarzábal: una malagueña en la corte del rey Gustavo», Jábega, no 92, 2002, pp. 111122. Ma Luisa Mateos «Isabel Oyarzábal de Palencia y sus artículos en Blanco y Negro (19251928)» en Ma J. Jiménez y otras (coords.), Escritoras españolas e hispanoamericanas en el exilio, Málaga, Servicio de Publicaciones de la Universidad de Malaga, 2005, pp. 205-218. Neus Samblancat, «Isabel Oyarzábal Smith, una mujer moderna», en A. Díez (eds.), Ateneístas ilustres II, Madrid, Ateneo Científico, Literario y Artístico de Madrid, 2005, pp. 529-538. Giuiliana Di Febo, «Isabel de Palencia: una republicana en la Sociedad de Naciones», en M. Nash (coord.), Ciudadanas y protagonistas históricas. Mujeres republicanas en la II República y la Guerra Civil, Madrid, Cuadernos del Congreso de los Diputados, 2009, pp. 129-146. Concepción Bados, «Isabel Oyarzábal Smith: la escritura como compromiso social y político», en Ma J. Porro (eds.), Escritoras andaluzas y exilio, Córdoba, Universidad de Córdoba-Diputación de Córdoba, 2010, pp. 123-148.

7. Olga Paz, Isabel Oyarzábal Smith (1878-1974): Una intelectual en la Segunda República española. Del reto del discurso a los surcos del exilio, Sevilla, Junta de Andalucía, 2010. 
La creatividad literaria de Oyarzábal se repartió entre España y el exilio en México. Los libros publicados en Madrid anteriores a 1936 fueron El alma del niño. Ensayos de psicología infantil (1921), Diálogos con el dolor (1921), El sembrador sembró su semilla (1923), y El traje regional de España: su importancia como expresión primitiva de los ideales estéticos del pais (1926). En New York y México, dependiendo de los idiomas en que fueron escritos, salieron al mercado literario Saint Anthony's Pig (1939?), Juan, son of the fisherman (1939), I must have liberty (1940), una recopilación de su antigua obra teatral actualizada Diálogos con el dolor (1944), Smouldering Freedom. The Story of the Spanish Republicans in Exile (1946), Alexandra Kollontay, Ambasadress from Russia (1947), En mi hambre mando yo (1959) y Del Diario yantar (cocina hogareña) (1951). Además, debemos señalar un conjunto de unas cuarenta obras inéditas depositadas en la Biblioteca Nacional de México8.

La escritora realizó también traducciones de obras que le proporcionaron una fuente de ingresos económicos nada despreciable. Por un lado, tradujo documentos para los organismos internacionales como representante española en la OIT y la SN, así como discursos y conferencias pronunciados a favor de la II República en Gran Bretańa y Estados Unidos. Por otro, las versiones de novela y teatro de los autores Henry Irving, Jane Austen, Havelock Ellis, Edgard Westermarck, Arthur Conan Doyle y George Elliot. Los temas de las traducciones abordaron desde la sexualidad $(\mathrm{H}$. Ellis) a las grandes novelas inglesas (G. Eliot y J. Austen), el espiritismo (C. Doyle), el teatro (E. O’Neill), la novela rosa (C. Merrel) o los libros de cocina, siendo la lengua asidua el inglés, aunque también tradujo del francés e italiano. Esta actividad profesional se enmarca en el contexto de su identidad, es decir, una persona culta de la burguesía intelectual integrada en la sociedad elitista de la capital, bilingüe, cosmopolita e implicada en la política progresista de la República.

Los asuntos que atrajeron su atención fueron la mujer, el niño, la educación y los derechos sociales, aunque también podemos encontrar un importante conjunto de textos periodísticos vinculados a temas tradicionalmente femeninos como la moda, la belleza, la decoración y el hogar. A continuación analizaremos las obras donde planteó problemas y una propuesta particular de regeneración del país desde el punto de vista de una mujer moderna en la España de los años treinta.

\section{LA EDUCACIÓN COMO REQUISITO PARA LA REGENERACIÓN DEL INDIVIDUO Y LA NACIÓN}

Oyarzábal estaba acostumbrada a la escritura desde que en diciembre de 1907 comenzó la publicación de la revista para mujeres La Dama. Mundo, música, modas, el primer proyecto periodístico y el más personal de su trayectoria. La

8. Recogidas en Nuria Capdevila-Argüelles, Autoras inciertas. Voces olvidadas de nuestro feminismo, op. cit., p. 61. 
práctica profesional, sin embargo, la ejercitó con la corresponsalía del periódico londinense The Daily Herald, mientras que la fama le llegó con el seudónimo de «Beatriz Galindo» en el diario El Sol, el de mayor fama y calidad de los años de entreguerras. En esta cabecera reflexionó sobre la educación, las desigualdades entre sexos, el feminismo y cuestiones femeninas que atraían a lectoras de los medios de comunicación de masas, como la belleza o la moda.

A principios de los años veinte Oyarzábal había consolidado su personalidad, formulados sus principios y valores, y los medios para exponerlos: el periodismo, la literatura, el feminismo, el asociacionismo y la militancia política en el socialismo. Seguirá la trayectoria del feminismo español que comenzó con preocupaciones sociales y educativas para posteriormente hacerse político a través de la lucha por la igualdad legal entre sexos. Cuando se dispuso a escribir su primera obra de ficción en 1923, se hallaba en una situación acomodada, y era una de las protagonistas del reducido colectivo femenino implicado en la lucha por los derechos de la mujer.

Las obras de su repertorio literario que trataron con intensidad cuestiones relativas a la educación son el ensayo El alma del niño. Ensayos de psicología infantil $(1921)^{9}$ y la novela El sembrador sembró su semilla $(1923)^{10}$. Con ellas se introdujo en algunas de las ideas centrales del discurso científico, político y cultural de la época al abordar la idea de la regeneración necesaria de la sociedad desde sus orígenes, es decir, la gestación y la infancia.

La redacción de El alma del niño y de su segundo ensayo, El traje regional de España: su importancia como expresión primitiva de los ideales estéticos del pais (1926), llevaron a la escritora a ser incluida en la nómina reducida de ensayistas españolas en cuya cabecera se sitúa María Zambrano como la más importante de la Edad de Plata. La educación del hombre y de la mujer (1892) de E. Pardo Bazán y La mujer del porvenir (1868) de C. Arenal representaron hitos importantes en estos estudios genéricos escritos por mujeres que tanto proliferarían en el periodo de entreguerras. J. C. Mainer ha puesto de manifiesto que el ensayo suele extenderse en tiempos de cambio y relativismo, en periodos donde existe confusión, inseguridad y crisis que favorecen la reflexión y la escritura de pruebas o tanteos que intentan ofrecer soluciones poco exploradas ${ }^{11}$. Las ensayistas, pues, pretendieron contribuir con sus análisis a la construcción de una nueva sociedad y convertirse en actores del tiempo en el que vivieron.

Según José Ortega Munilla, padre del filósofo José Ortega y Gasset y prologuista de El alma del niño, la obra pretendía buscar el origen de la diferencia espiritual de cada individuo y aprovechar su fuerza actitudinal para su propio beneficio y de la colectividad. En el ensayo era evidente la connotación maternal y la crítica a la política social de los gobiernos de la Restauración que

9. Editado por V. H. Sanz Calleja Editores e Impresores. Lo firmó con su nombre y su seudónimo, Beatriz Galindo.

10. Librería Editorial Rivadeneyra, Madrid.

11. Jesús Gómez (ed.), El ensayo español, prólogo de José-Carlos Mainer, Barcelona, Crítica, 1996. 
descuidaba a las capas más débiles. Estaba subyacente la intención de rehabilitar la sociedad a través de la recuperación de la mujer, dejando atrás el aislamiento en el hogar y la inferioridad social, política, legal y económica que padecía.

Isabel planteaba un método de educación basado en sugerencias y consejos más que en imposiciones autoritarias, e hizo hincapié en la necesidad de que se promulgaran leyes de protección a la infancia y a la maternidad. La autora consideraba que, cuidando y educando adecuadamente a los nińos, se conseguía personas responsables para el futuro ${ }^{12}$. A su juicio, la educación de las mujeres era esencial para lograr este objetivo, puesto que sólo con madres bien instruidas se lograba un adecuado aprendizaje en habilidades sociales, en normas de convivencia y en igualdad. Oyarzábal expuso la necesidad de corregir la vanidad, la terquedad, la envidia, la ira, el egoismo, la crueldad o la falta de generosidad en los primeros ańos de vida, puesto que era una tarea beneficiosa tanto para el individuo como para el colectivo. Combatir la mentira, el miedo y alimentar una curiosidad sana hacia el entorno, ayudaba a construir un mundo mejor.

En el ensayo elevó su propuesta a valores más generales como el sentimiento patriótico, el religioso, la libertad, el sentido de la lógica o el concepto del derecho, unos principios básicos de comportamiento que habían de ser inculcados desde la niñez. Oyarzábal, a caballo entre el siglo XIX y XX, veía la solución capacitando a la mujer para comprometerse con una maternidad responsable, una opinión que compartían Federica Montseny, Elena Fortún o Hildegart Rodríguez, quienes asociaron la pedagogía y la puericultura con la política. Su propuesta era una especie de maternidad politizada en la que la madre ejercía de educadora y de agente de la socialización y compromiso de sus hijos con la sociedad. La madre debía tener conocimientos y una "política" clara sobre todos los asuntos relacionados con el bebé, incluso los aspectos cotidianos, como el aseo, la alimentación, la lactancia o el juego, porque el niño estaba vinculado a la patria, a la prosperidad y al progreso. Esta orientación de la maternidad será parte de su proyecto de reforma nacional partiendo de su posición como mujer y madre.

La constancia de las duras condiciones de vida de las trabajadoras embarazadas y la falta de una asistencia adecuada quedarán en evidencia en sus páginas y las utilizará para su discurso combativo desplegado en otros foros. En El alma del niño demandó una legislación que potenciara los derechos de las madres trabajadoras y de los hijos, que prohibiera el trabajo infantil y la regulación de la jornada laboral femenina.

Sus opiniones respecto a la educación infantil quedaron patentes en este ensayo y en el conjunto de columnas de $\mathrm{El} \mathrm{Sol}$, en las que exhibió su tendencia de mujer cosmopolita y europea que abogaba por el conocimiento de otras culturas, un principio básico en la Institución Libre de Enseñanza, el Instituto

12. Victoria Ferrer y Esperanza Bosch, «El alma del niño: Ensayos de psicología infantil: una obra olvidada de una mujer olvidada», Revista de Historia de la Psicología, 21, 2-3, 2000, pp. 8594. 
Escuela, la Residencia de Señoritas y otros organismos coetáneos que frecuentó. No obstante El alma del niño no fue un estudio académico o un trabajo de investigación, sino una reflexión sobre las condiciones de vida alentado por la necesidad de definirse ante los cambios que comenzaban a ser palpables en la sociedad española. Al igual que otros textos coetáneos no pretendió ser exhaustivo, sino ilustrar, apoyar opiniones y rebatir las de aquellos que sostenían teorías y prácticas contrarias a sus planteamientos.

Los primeros juicios críticos, incorporados en la primera edición, se deben a la pluma de María de Maeztu, directora de la Residencia de Señoritas, y la maestra Benita Asas, quienes lo evaluaron con comentarios muy positivos. La prensa lo presentó como un estudio inteligente de la mente infantil y como la obra más completa sobre el tema aparecida hasta el momento. El periodista José Francos Rodríguez, presidente de la Asociación de la Prensa de Madrid, dirigió sus elogios a esta primera obra de B. Galindo en cuanto que se centraba en los problemas físicos y emocionales de la niñez, una cuestión fundamental para el desarrollo nacional. La periodista Carmen de Burgos, Colombine, escribió una reseña en El Heraldo de Madrid ${ }^{13}$, en la que destacaba el hecho de que la producción de libros escritos por mujeres resultaba una demostración de que se estaban extendiendo los conocimientos y las aficiones que antes eran privativos de una elite. Decía «(...) es el suyo un libro de gran educadora, de gran profesora de Pedagogía en donde pueden aprender las profesionales porque el trabajo de Beatriz Galindo no es un trabajo didáctico. (...) El alma del niño ha puesto su ternura de madre, su alma de artista, sus dotes de mujer buena, dulce, observadora ${ }^{14}$. C. de Burgos se refería en su comentario al debate sobre la identidad femenina, objeto de su atención en La mujer moderna y sus derechos (1927), y también de M. Nelken en La mujer y el amor en el proyecto de nuevo código penal (1928) o de M. Huici en El problema engenésico: punto de vista de una mujer moderna (1930). En el texto de Oyarzábal, al igual que en los señalados, hay un tono incisivo que reclamaba el final de los prejuicios morales, religiosos y, sobre todo, la desigualdad educativa femenina, una de los calamidades endémicas de la patria.

En esta línea de denuncia de algunos problemas nacionales, se encuentra la novela El sembrador sembró su semilla, cuya trama aborda también la educación y sus implicaciones con la sexualidad. Los intelectuales de la época le dieron una buena acogida si nos atenemos a la correspondencia de felicitaciones y reconocimientos que sostuvo con José Martínez Ruíz -Azorín-, y al homenaje que le rindieron numerosos escritores, periodistas y artistas en el Hotel Palace de Madrid como Victoria Kent, Luís Araquistain, Ramón Pérez de Ayala, Concha Espina, María de Maeztu, Juan Ignacio Luca de Tena y Cipriano Rivas Cherif,

13. 30 mayo 1922, pág. 2.

14. Fue reeditado en México por Ediciones Aztlán en 1958 con una edición de 3.000 ejemplares. En esta ocasión fue reseñado en Claridades y Novedades el 16 de noviembre de 1958 así como en El Socialista Español en enero de 1959. Fondo Isabel Oyarzábal. Vol. 6. Publicaciones y obra periodística. ANC. 
entre otros ${ }^{15}$. El Sol y El Heraldo de Madrid divulgaron la publicación de la novela con varias reseńas laudatorias. A. Ballesteros de Martos, por ejemplo, decía:

Admirable novela. Aquí es la vida lo que ante todo y sobre todo preocupa y está reflejada con tal intensidad y con tal emoción, hay tanto amor y tanta humanidad en sus páginas que su eco perdura en nuestra mente y nuestro corazón después de ser leídas. Beatriz Galindo en sus primicias como novelista nos hace concebir muy fundadas y halagüeńas esperanzas. (...) Sobre el tema ya vulgar de la trascendencia y significación del matrimonio, ha sabido componer, sin falsos pudores ni enfermizas procacidades una novela que hace sentir y pensar ${ }^{16}$.

La novela estaba centrada en el tema de la herencia y se introducía en los efectos de la ignorancia de la mujer sobre su propio cuerpo y la maternidad, enlazando con las preocupaciones regeneracionistas sobre el cuidado de la sociedad desde el momento de la concepción, y con su ensayo sobre el alma del niño. Era una narración en tercera persona donde la voz protagonista intentaba desmontar la falsa moral de una ciudad provinciana de principios del siglo XX y el impacto que tenía en la heroína, Mónica González de la Roca. Esta joven mostró una profunda rebeldia contra la educación recibida, aunque era una rebeldía contradictoria y llena de conflictos, como lo era en ese momento el de las mujeres intelectuales o el de la propia autora. Su destino trágico se cumplió cuando dio a luz a un bebé que morirá debido al contagio de una enfermedad sexual transmitida por su padre.

El título se conformaba como un símil en el que el hombre sembraba la tierra de forma insconciente e irresponsable, llevado por instintos, mientras que la mujer reaccionaba de forma pasiva y sumisa, ignorante e imprudente. Ambos actuaban pensando en satisfacer sus deseos a corto plazo, obviando las consecuencias de una conducta basada en el hedonismo. De ahí que no hubiera frutos sanos y que con su actitud se aniquilara la tierra dejándola estéril para la sociedad. El argumento, por tanto, está vinculado a la convicción de Oyarzábal de que si la mujer adquiría conocimientos, estos errores se corregirían y habría una posibilidad de regeneración, al igual que ocurría con la patria si se practicaba una política basada en la educación de los ciudadanos.

En El sembrador se encuentra una parte de la experiencia personal de la autora, puesto que en su autobiografía reconoce una profunda ignorancia en materia sexual hasta el momento en que tradujo la obra de Havelock Ellis Estudios de psicología sexual (1913). Este desconocimiento era aún más grave si tenemos en cuenta que contrajo matrimonio en 1909 y fue madre al año siguiente. En la novela, la escritora reflejó implícitamente que la elevada tasa de analfabetismo de la mujer en España, aproximadamente el 71,4\% en 1900 y el 47,5 \% en 1930, repercutía negativamente hasta en los asuntos más privados, como la maternidad, el embarazo y el amor. Y de su lectura se infería

15. El Sol y El Heraldo de Madrid, 1 de marzo de 1923. La nota social del homenaje, en ambos periódicos el 6 de marzo de 1923, pág. 4.

16. El Sol, 9 de febrero de 1923 , pág. 5 . 
la necesidad de mejorar la formación y la eliminación de tabúes perjudiciales para la salud y la higiene.

Isabel Oyarzábal había planteado estas propuestas en sus artículos periodísticos, en los que era habitual que abordara el derecho a la educación. La cultura de las españolas y, en concreto, el hábito de la lectura, fueron objeto de largos párrafos en las secciones de "Diario de la Mujer» y «Crónicas femeninas» del periódico $\mathrm{El} \mathrm{Sol}$. La escritora concebía la lectura como un medio fundamental para comunicarse intelectualmente con hombres, disminuir las desigualdades entre sexos y acabar con la tradición de un país atrasado que veía con malos ojos el que sus mujeres leyeran. Bajo el titular «De la cultura y la educación de la mujer en España», reprobaba el retraso de la implantación de mejoras en las condiciones de la mujer y alentó una solución, en cierto modo personal, a falta de una política estatal, en la que incluía la cultura individual, el esfuerzo, el desarrollo de las capacidades por medio de una disciplina adecuada, el fomento de la responsabilidad, la autoinspección o el conocimiento de sí mismo ${ }^{17}$.

Oyarzábal calificaba de drama el retraso que España acumulaba en mejorar la condición de la mujer comparado con el avance que se estaba registrando en los países occidentales, si bien reconocía la existencia de mujeres insignes como María de Maeztu, ejemplo de una generación nueva que se disponía a perseguir con ahínco el desarrollo de su potencialidad. A su juicio la mujer no tenía asumido el concepto de responsabilidad porque ni la religión, ni las costumbres ni la ley habían ayudado a desarrollarlo. Oyarzábal propugnaba que la mujer debía dominar su voluntad, conocer sus responsabilidades, sus derechos y su misión, como únicas vías para mejorar su condición ${ }^{18}$.

Esta convicción de que el problema de la ignorancia era uno de los más relevantes del país, se manifestó igualmente en las conferencias que I. de Palencia impartió en los ańos 1920-1930 tanto en España como en Estados Unidos y Canadá en el contexto de una gira que realizó para promocionar uno de sus libros de más éxito, El traje regional de España. Su importancia como expresión primitiva de los ideales estéticos del país (1926) ${ }^{19}$. A la vuelta de este viaje que la dio a conocer internacionalmente, pronunció algunas charlas en la Residencia de Seńoritas de Madrid, el primer centro oficial destinado a fomentar la enseńanza universitaria para mujeres. En él, las jóvenes pudieron oir las disertaciones de Oyarzábal relativas a las escritoras contemporáneas, las mujeres de clase media y su papel renovador, su experiencia viajera a Estados Unidos o la estética, en un ambiente en que se invitaba a conferenciantes y estudiantes a compartir opinión sobre la cultura y los dilemas del momento ${ }^{20}$. La solución que sugería era clara: educación e igualdad entre sexos.

17. Artículo completo en El Sol, 23 de agosto de 1918, pág. 2.

18. El Sol, 23 agosto 1918, pág. 2.

19. Fondo Isabel Oyarzábal. Vol. 6 Conferencias, ANC.

20. Al respecto, Raquel Vázquez, Mujeres y educación en la España contemporánea. La Institución Libre de Enseñanza y la Residencia de Señoritas de Madrid, Madrid Akal, 2012, pp. 244254. Igualmente, Carmen de Zulueta y Alicia Moreno, Ni convento ni college. La Residencia de Señoritas, Madrid, Residencia de Estudiantes, 1993. 


\section{LAS CAUSAS DEL CONFLICTO BÉLICO DE I936: UN TESTIMONIO DESDE LA PERSPECTIVA DE MUJER COMPROMETIDA}

Las escritoras y las periodistas aprovecharon la oportunidad del exilio y de la demanda de información sobre la Guerra Civil para narrar las circunstancias dramáticas que habían vivido. La dolorosa experiencia de un conflicto nacional, largo y extremadamente violento y la obligación de abandonar su país, marcaron su estado anímico y fomentaron una necesidad psicológica de contar la versión de los hechos vividos en los ańos de su juventud y madurez, lo cual explica la abundancia de narraciones autobiográficas publicadas en la década de 1940-1950. Entre las obras pioneras destacan: Éxodo, de Silvia Mistral (1940); Primer Exilio, de Ernestina de Champourcin (s/f); Primer Frente, de M. Nelken (1944); Europa fugitiva. 30 estampas de la guerra, de María Enciso (1944); I must have liberty y Smouldering freedom de Isabel de Palencia (1940 y 1945 respectivamente) y Él, de Mercedes Pinto (1948). La sociedad mexicana, interesada entonces por los acontecimientos de la guerra contra el fascismo en Europa, acogió bien estos textos publicados en editoriales mexicanas, norteamericanas y, en muchos casos, en empresas de los propios exiliados.

La naturaleza de la experiencia del destierro delata una de las características más constantes de la literatura del exilio: una predisposición al testimonio incluso cuando aparentemente la intención de los autores fuera muy distinta. Por este motivo algunos exiliados recurrieron a la autobiografía como defensa eficaz ante la condición de desterrado. James Olney afirma que escribir sobre su propia vida es crear una nueva identidad extraída de entre una variedad de otras anteriores ${ }^{21}$. El exilio crea nuevas identidades al producirse la distancia necesaria para mirarse a sí mismo de una manera objetiva, desde una situación diferente y desde una tierra distinta. El exiliado siente una necesidad de dejar testimonio de su vida, y a esta necesidad se le suma una obsesión que ha afectado a más de un desterrado, el olvido, su opuesto dialéctico. La ingente cantidad de libros de memorias sirve para ilustrar su necesidad de recuperar y compensar esa experiencia, así como también para dotar de independencia a los recuerdos en relación a la experiencia real ${ }^{22}$.

No obstante, la escasa visibilidad de las intelectuales, políticas y artistas en el exilio es sorprendente si la comparamos con la de sus homólogos masculinos. La guerra había acrecentado la incorporación a la vida pública de las mujeres y las había lanzado a la organización política y militar, al frente o a la fábrica. En el exilio, en cambio, convergieron factores generales y específicos que determinaron un retroceso radical de dicha incorporación, afectando a la producción literaria y artística femenina como consecuencia de la precariedad de la nueva situación, el proceso de adaptación al medio, la dedicación a la familia y su paso a un hipotético segundo plano.

21. James Olney, Studies in Autobiography, Oxford, Oxford University Press, 1988.

22. Un estado de la cuestión en Mónica Moreno Seco, «Las exiliadas, de acompañantes a protagonistas", Ayer, 81 (I), 2011, pp. 265-281. 
Según los estudios de P. Dominguez Prats, C. Lida y A. Alted, las mujeres fueron actores clave en la integración de sus familias en las sociedades de recepción, y a la vez "guardianas» de las tradiciones y de la cultura españolas ${ }^{23}$. Una vez más dejarán para otro momento sus propias demandas a favor de otras causas prioritarias, como la lucha antifranquista o el mantenimiento de una España republicana extraoficial y sin territorio, y constituirán una herramienta básica en la perduración, la memoria de la libertad y la democracia, pero su labor pertenecerá y permanecerá en el terreno doméstico y emocional. Este legado lo reflejarán a través de su escritura que será una memoria reflexiva del pasado, fragmentada, diseminada y poco leída ${ }^{24}$.

I. de Palencia fue una de las mujeres que tuvo que renunciar a vivir en la España de Franco. De forma incipiente y siendo consciente de su destino inmediato, el 13 de marzo de 1939 acudió a una reunión en París con veinte españoles más entre los que se incluía a Josep Carner, Corpus Barga, Rodolfo Halfter, Tomás Navarro, Eugenio Imaz y Joaquín Xirau. El grupo acordó la necesidad de proveer a los intelectuales de un marco institucional que evitara la dispersión y permitiera mantener viva a la República. Con este objetivo fundaron la Junta de Cultura Española (JCE), eligiendo a José Bergamín como presidente. En sus estatutos figuraba como principal objetivo el rescate de la cultura, una operación que implicaba asegurar las vidas de cientos de españoles facilitando su evacuación a Iberoamérica. La «cultura» fue representada como una «entidad» amenazada y como una actitud que podría prevenir la dispersión y su práctica desaparición. Consecuentemente la mayoría de las actividades se hicieron bajo la cobertura del Servicio de Evacuación de los Republicanos Españoles (SERE) y de la Junta de Cultura Española (JCE).

Oyarzábal gozaba de una trayectoria muy conocida desde su posición de activista, su militancia feminista, la filiación socialista, las incontables intervenciones en foros internacionales, su producción periodística y literaria o el hecho de haber sido la primera y única mujer embajadora de la República. En México continuó con gran parte de las actividades que desarrolló en España, es decir, el asociacionismo y las relaciones públicas, la oratoria, el periodismo, la propaganda y la escritura.

En su faceta de escritora los años del exilio fueron muy prolíficos, como lo muestran los textos autobiográficos y los que escribió que han permanecido inéditos. Una vez que su familia se estabilizó en el plano de la infraestructura doméstica y económica, desarrolló su obra literaria más importante sin

23. Pilar Domínguez Prats, Voces del exilio. Mujeres españolas en México, 1939-1950, Madrid, Comunidad de Madrid, 1994. Alicia Alted, «Mujeres españolas emigradas y exiliadas. Siglos XIX y XX», Anales de Historia Contemporánea, 28, 2008, pp. 59-74. Clara Lida, Inmigración y exilio. Reflexiones sobre el caso español, México, Siglo XXI, 1997. Dolores Plá Brugat, (coord.), Pan, trabajo y hogar. El exilio republicano español en América Latina, México, SEGOB-Instituto Nacional de Migración, 2007.

24. Josebe Martínez, «Hegemonía intelectual, exilio y continuidad histórica», en M. Aznar (eds.), El exilio literario español de 1939: actas del Primer Congreso Internacional, Barcelona, GEXEL, 1995, pp. 324-331. 
abandonar la colaboración en medios de comunicación y las conferencias. Como hemos señalado en páginas anteriores, recién llegada a México escribió dos títulos de literatura infantil dedicados a su nieto Juan Somolinos Palencia. El primero fue Saint Anthony's pig (1940, Longmans, New York), ilustrado por su marido Ceferino Palencia Tubau, que relataba una historia transcurrida en un pueblo malagueño en clara alusión a los recuerdos de su infancia en Alhaurín. De estilo similar sería Juan: son of the fisherman (1941, Longmans, New York), igualmente ilustrado por C. Palencia con dibujos de pescadores típicos malagueños. Ambos, especialmente el segundo, fueron reseñados en la prensa norteamericana con notable éxito.

Los dos libros de contenido autobiográfico escritos en inglés son: I Must have Liberty (1940) y Smouldering Freedom. The Story of the Spanish Republicans in Exile $(1945)^{25}$. Se publicaron en Estados Unidos como respuesta a la demanda social de conocimiento sobre la Guerra Civil y a que la editorial confiaba en ella por ser una autora famosa y por haber participado en la misión diplomáticopropagandística que realizó a lo largo de Estados Unidos y Canadá en el otoño de 1936.

I. de Palencia pretendía ofrecer su testimonio sobre lo ocurrido en España al igual que lo hicieron otras mujeres contemporáneas que se vieron obligadas a marchar al exilio. En sus trabajos es difícil discernir entre lo público y lo privado y son clave para diseccionar el papel de las mujeres y comprobar el modo en que alteraron la sociedad tradicional en una Espańa rígidamente anquilosada. Estas autobiografías, según $S$. Legott, se han conocido poco y tarde, debido no sólo a razones políticas y de exclusión social de las exiliadas, sino a razones técnicas basadas en que no son aceptadas como un "género" en el ámbito literario sino que se consideran otras formas de literatura ${ }^{26}$. Sin embargo, la creciente proliferación de estudios de textos autobiográficos y la recuperación de narrativas personales están sirviendo no sólo para conocer los acontecimientos con testigos de lo acontecido, sino para construir la historia de una tradición femenina, la escritura.

Para Oyarzábal escribir las autobiografías suponía la continuidad de su compromiso político, una posibilidad de poner de manifiesto los conflictos vividos en el pasado que explicaban el origen de su actual presente. En ellas narró, en clave personal, la historia española de las primeras décadas del siglo XX y ensalzó los principios ideológicos, los valores y la práctica de la II República. En estas obras dejaba ver su evolución personal y política desde posiciones conservadoras propias del origen social de su entorno familiar, a otras progresistas identificadas con la II República, hasta el punto de poner su trayectoria al servicio de la misma. Esta es la idea dominante en ambos textos, en los que relega a un segundo o tercer plano su militancia en movimientos

25. Ambos publicados por la Editorial Longman en New York. Originales en Fondo Isabel de Palencia. Archivo Nacional de Cataluña.

26. Susan Legott, History and autobiography in contemporary Spanish women's testimonial writings, New York, The Edwin Mellan Press, 2001, p. 10. 
como el Consejo Supremo Feminista. Es de destacar, igualmente, una palabra frecuente e incluida en los títulos, «libertad» («liberty», "freedom»), un concepto que deseaba convertir en práctica y en forma de vida, un término que perseguirá hasta alcanzarlo a través de su defensa a favor de la igualdad y la lucha por los principios sociales y políticos presentes en la Constitución de 1931. La importancia de la «libertad» estaba enfocada en los dos sentidos posibles de alcanzar desde su naturaleza femenina: la política y el género.

I must have liberty (1940), debe interpretarse como un documento de historia política y cultural con el propósito de informar al mundo sobre su perspectiva de los sucesos en España. Al año siguiente fue traducido al sueco como Jag máste ha frihet (Debo tener libertad, Estocolmo, Albert Bonniers Förlag, 1941) con motivo del interés que suscitaba en Suecia conocer los recuerdos de quien había sido una embajadora especial. El núcleo narrativo se basa en su vida supeditada y relacionada a los principales acontecimientos históricos que vivió. El título, donde enfatiza «I» y «must», evidencia la firmeza y fortaleza de su carácter, y refleja la voluntad de exponer su experiencia vital y opinión en primera persona, a diferencia, por ejemplo, de la obra de Constancia de la Mora In Place of Splendor: The Autobiography of a Spanish Woman, en la que destaca la colectividad frente a la identidad individual ${ }^{27}$.

En este primera entrega autobiográfica narraba su infancia en la Málaga de finales del siglo XIX como una niña de clase burguesa que experimentó un desarrollo emocional e intelectual en el colegio, en la comunidad familiar y en su madurez, cuando se topó con la guerra y el exilio. En ella refleja su deseo de libertad desde su infancia, cuando se siente acorralada en el colegio de monjas donde ingresa con siete años y en el que permanecerá hasta completar su formación a los catorce. En sus recuerdos manifiesta la necesidad que siente de ser libre, de verse liberada de una reglamentación estricta en el contexto de un colegio confesional en la España finisecular. Sólo los viajes a Escocia y los veranos pasados en su casa veraniega situada en el interior de la provincia, parecen descargarla del control eclesiástico. Precisamente el aprendizaje vital de las vacaciones estivales saldrán a relucir en la novela escrita posteriormente titulada En mi hambre mando yo.

La autora siguió un orden temporal en el que respetaba los acontecimientos de la realidad, aunque hay fechas erróneas y el orden que siguió fue selectivo, según debió aparecer en la memoria y en sus prioridades. De esta manera enlazaba experiencias y hechos del pasado con otros más recientes, y el relato está impregnado de su condición bilingüe, de su infancia y adolescencia, de la problemática social y de su actividad profesional como periodista y oradora. Isabel dió un simbolismo a los lugares donde transcurrió su vida, plasmando cada uno una etapa e identificándolos con hechos y también con escritos. Málaga, Escocia, Madrid (en los distintos domicilios en los que residió y los círculos sociales que frecuentó), Ginebra, Estocolmo, New York y México, representan una clave para entender su trayectoria pública e ideológica. En

27. New York: Harcourt, Brace and Co., 1939. 
México se asienta y viaja hacia el pasado y el recuerdo, una ciudad que la acoge bien pero en la que intuye la imposibilidad del retorno. También cita nombres de personas que tuvieron una influencia en su experiencia vital como Alexandra Kollontay, M. Nelken, Clara Campoamor, la premio Nobel de Literatura Pearl S. Buck, sus compañeras del Lyceum Club especialmente V. Kent o políticos como Azaña, Madariaga, Álvarez del Vayo o Araquistain.

La admiración y el ensalzamiento hacia la causa republicana expresadas tras la derrota militar y desde el exilio, tenían como finalidad mostrar ante el mundo los antecedentes y el desarrollo de la Guerra Civil, la reacción del pueblo ante el ataque fascista a un régimen democrático y la legitimidad del estado republicano. La autobiografía está escrita desde su presente, el de los primeros años del exilio en México, pero los años de la República serán los que marquen el eje de la narración. En ella hace visible algunos de los conflictos sociales, económicos y políticos heredados desde épocas anteriores, y su desenlace fatal en el enfrentamiento civil de 1936. Desde su punto de vista, las diferencias sociales, la mala distribución de la riqueza, la ausencia de una formación política, la nula educación de la población, especialmente de las mujeres y su relegamiento al hogar, así como la resistencia de las clases privilegiadas a perder ámbitos de poder, eran algunas razones que explicaban el estallido de la guerra. Su opinión no corresponde a la de una mujer de pensamiento radical, sino más bien a una persona burguesa de ideología de izquierdas que vio en la política reformista de la II República la solución a la mayor parte de las cuestiones que asolaban a España desde hacía décadas y que permanecían sin resolver.

El texto tuvo una buena recepción entre el público y una gran repercusión mediática a tenor de las más de 47 reseñas publicadas en prensa norteamericana entre finales de noviembre y principios de enero de 1940 e incluso todavía se pueden encontrar algunas en 1943. Entre ellas destacan las incluídas en The Republic, The New York Times, The New York Sun, New York World Telegram, New York Herald Tribune, Dallas Herald, New York Post, The Boston Herald, Baltimore Sunday Sun, Worcester Sunday, The Nation, Chicago Tribune y New York American. Igualmente The Women's National Book Association y The Bookseller's League of New York auspiciaron encuentros de Isabel con la prensa para la divulgación de su libro, muy bien acogido entre el público norteamericano, incluida Eleanor Roosevelt, la esposa del presidente ${ }^{28}$. Las reseñas destacaron los orígenes sociales de la autora así como el hecho de constituir no sólo una autobiografía sino la historia de un país. Algunas destacaron su proyección internacional como delegada de la República en la Sociedad de Naciones o embajadora en Suecia, es decir, la divulgación de una identidad moderna y rupturista con el modelo de mujer tradicional espańola. El New York Herald Tribune consideró que era la mejor autobiografía escrita fuera de España.

La segunda parte de su vida la escribió algún tiempo después bajo el título Smouldering freedom. The story of the Spanish republicans in exile (1945), y

28. Fondo Isabel Oyarzábal, Vol 6. Publicaciones y obra periodística, ANC. 
respondía al relato de su experiencia vital a partir del final de la Guerra Civil. Lo dedicó a México, real land of freedom for thousands of Spaniards and with heartfelt thanks to the Committee of Aid to Spain and to all whose generosity made that aid possible ${ }^{29}$. Se editó también en Londres en 1946 y fue traducido al holandés con el título de Vrijheid in ballingschap (Libertad en el exilio, Uitgeverij Elmar, Ámsterdam).

En Smouldering freedom se identificó con los exiliados que no tuvieron un trato privilegiado como el que le correspondió a ella al ser diplomática. Frente a I must have liberty, este segundo texto incluye un recuento personal del periodo postbélico, pero una parte sustancial de la narrativa es protagonizada por la memoria de otros. Es un testimonio histórico, una «historia vivida» de los primeros años de su exilio en México que no persigue la sistematización histórica como ocurre en las obras de Mauricio Fresco La emigración republicana española: una victoria de México (1950), o de Carlos Martínez en Crónica de una emigración (1956), sino la interpretación de su experiencia.

En esta obra Oyarzábal ofrece una visión retrospectiva en la que se observa su trayectoria personal pero también la reconstrucción de la historia colectiva de los últimos meses del conflicto, la salida de los republicanos por la frontera pirenaica, los campos de concentración y el plural destino de sus compatriotas. Es una visión trágica, como lo fueron los últimos meses de la contienda, en la que refleja una percepción negativa de la política y los políticos, llevados por la cobardía, los intereses económicos y los egoísmos. Una conjunción de actitudes que, desde su punto de vista, condujeron a un dramático final para la propuesta modernizadora y reformista republicana. I. Oyarzábal no acusa a nadie en particular, sino a la coyuntura internacional, a los poderes económicos, a la falsa moral de la diplomacia y de los líderes internacionales, así como a las presiones de los grandes empresarios.

En esta segunda autobiografía describe su angustia personal como madre y esposa, alejada de su familia como consecuencia de su destino en Oslo y desconocedora del paradero de sus más allegados. Narra los primeros años de su estancia, las dificultades financieras y personales hasta la instalación definitiva en el destierro. Poco a poco se introdujo en su vida de futuro, que será fuera de la geografía espańola acogida en el exilio mexicano, donde irá reconstruyendo la estabilidad familiar y económica y las actividades comunes a la mayor parte de los transterrados. La imagen que Oyarzábal ofrece de México es muy positiva, sobre todo se aprecia el agradecimiento que siente hacia el país y sus ciudadanos.

En sus páginas se pueden comprobar, igualmente, los contactos que mantuvo con antiguos amigos y políticos republicanos de gran relevancia como Fernando de los Ríos, ex embajador en Washington, a quien visitó en 1943-1944, Federico de Onís, J. Álvarez del Vayo o Victoria Kent, puesto que su casa fue lugar de reunión de muchos de ellos. No aparecen en ellas, sin

29. Palabras del prólogo de la edición original. Fondo Isabel Oyarzábal, Vol 6. Publicaciones y obra periodística, ANC 
embargo, las rupturas habidas entre los exiliados ni las diferencias ideológicas que desembocaron en enemistades duraderas. De Palencia no quiso exhibir las complicaciones de la convivencia política de la emigración republicana que impidieron la reconstrucción de una alternativa válida al régimen de Franco. En cambio se detuvo en el relato del proceso de asentamiento personal y profesional del grupo español.

En el año de su publicación, 1945, los republicanos todavía pensaban en la posibilidad de que las democracias obligarían a Franco a marcharse del poder o a adoptar alguna medida política a la que pudieran acogerse para un retorno seguro. Esta segunda parte de su biografía fue percibida como una nueva obra sobre el conflicto español y sus consecuencias sociales desde la visión de una mujer con mucho protagonismo político. El diario Chicago Sunday Tribune de 9 septiembre 1945 tituló su aparición como «Trágica saga de la guerra civil en España», e hizo referencia a que la autora de I must have liberty, recreaba de nuevo la hazaña de héroes y mártires españoles que lucharon, fueron apresados, torturados y muertos por la libertad.

Finalmente, su último libro publicado En mi hambre mando yo (1959), es una novela social donde deja patente su visión de género y sus ideas socialistas en la que enfrenta el amor con los conflictos entre clases sociales ${ }^{30}$. El título lo tomó de una conversación que tuvo con un campesino cuando era pequeña y pasaba los veranos en un pueblo del interior de la provincia de Málaga. Aquella experiencia directa de contacto con el hambre y la escasez tuvo consecuencias en su concepción de la sociedad.

Publicada en México después de veinte años del final de la Guerra Civil, la trama de este nuevo texto nos sumerge en un guión muy frecuente en la literatura: la protagonista se enamora de un joven pero el entorno social impide que mantengan una relación normalizada, de ahí que opte por el matrimonio con un señor mayor al que no ama. Pronto enviuda y se reencuentra con su amor inicial, aunque las circunstancias políticas de la guerra les complican la relación hasta el punto de que acaban teniendo un final trágico. Diana, la protagonista, acaba en el exilio embarazada de su amado muerto, en una prometedora tierra que la acoge a ella y a su futuro hijo. Prepara su nueva vida con la hermana del padre de su bebé, simpatizante de la derecha espańola, con quien decide convivir superando las diferencias ideológicas que llevaron al país al enfrentamiento. La novela, pues, está inspirada en la observación de la realidad social explicada a través de la trama amorosa entre los dos protagonistas, Ramón y Diana, hasta el punto de que se podría considerar perteneciente al género de novela rosa si no fuera por el fuerte contenido ideológico impregnado en toda la narración.

En el texto I. Oyarzábal aborda los problemas estructurales de la España latifundista donde son perceptibles las profundas desigualdades sociales a través de la comparación entre la tierra y la mujer, la maternidad y el hambre del campesinado andaluz. La escritora explica los problemas del latifundismo y el

30. Carta de 22 de junio de 1959. 246. ALA (archivo Luis Araquistain), 98-28. Correspondencia embajada España en Estocolmo, 1936-1937; 1958-1959. Archivo Fundación Pablo Iglesias. 
conservadurismo con el símil tierra/mujer desde el cual resalta que ambos no producen más porque el patriarca no se lo permite. La oligarquía y el patriarcado se presentaban no sólo como poderes caducos sino como elementos corruptos y perniciosos para la sociedad a los que había que combatir hasta el punto de un enfrentamiento civil. En las páginas se observa que Oyarzábal pensaba que ambos factores formaban parte del ser de España y habían de ser extirpados para siempre a fin de edificar una sociedad sana y libre de dependencias jerárquicas y económicas. La obra recibió numerosas críticas positivas en la prensa mexicana como El Excelsior, El Nacional, Tiempo y España libre y fue presentado en el Ateneo Español de México ${ }^{31}$.

En suma, la obra literaria de Oyarzábal es la de una mujer comprometida con la política y la sociedad del tiempo en que vivió. Sus escritos, tanto literarios como periodísticos, dan cuenta de su compromiso político y de sus principios ideológicos, combinando en ellos su mentalidad progresista y su respeto hacia la fe católica. En ellos proyecta una imagen de España negativa en la que tiene una importancia nuclear la ignorancia de gran parte de la población, especialmente de las mujeres, el atraso de sus políticas, la permanencia de privilegios ancestrales que impedían el progreso, y la ausencia de políticas regeneradoras y reformistas. De ahí que la escritora viera en la propuesta de la II República la salvación de la nación, en cuanto que ésta planteaba la extensión de la educación a todos los ciudadanos, la separación Iglesia-Estado, la concesión de derechos políticos como el sufragio femenino, la incorporación de las mujeres al espacio público, la reforma agraria, la reforma militar y ese largo etcétera de transformaciones esbozadas durante el primer bienio republicano.

Al recuperar su producción escrita y analizar sus mensajes, consideramos que se cumple con la digna tarea de divulgar el pensamiento y el legado de muchas mujeres de nuestra Historia todavía bastante desconocidas en la actualidad.

31. Reseñas en El Nacional, 21 junio 1959 por Rafael Sanchez de Ocaña; Excelsior, de 26 de junio de 1959; Tiempo, 27 de julio de 1959; Excelsior, de 29 julio de de 1953; España Libre, de New York 4 de marzo de 1960. Fondo Isabel de Palencia. Vol. 3. ANC. 